\title{
Cycling: do the health benefits of cycling outweigh the risks in Bangkok?
}

\author{
David Seale \\ Siam University, Bangkok, Thailand
}

\begin{abstract}
This research looks at the aspects of cycling in Bangkok and weighs up the fact that the population in Bangkok, similar to any other urban population, is becoming less active and this trend is raising concerns in Thailand. Cycling, like many other physical activities, that could be reversed dramatically, especially on such illnesses such as obesity and diabetes 2, but it's attempting to change habits and educating people of the benefits of regular exercise and reversing this trend. This study then identified many of the concerns of cycling in Bangkok that were brought up by the qualitative research, aspects such as congestion, noise, pollution and the dangers of Bangkok roads, which are the second only to Libya for deaths.
\end{abstract}

Keywords: cycling, Bangkok, pollution, diabetes, noise, obesity, exercise, cycling in Bangkok, benefits of cycling, problems to encounter in Bangkok.

\section{INTRODUCTION}

From a societal point of view, a shift from the usage of car and public transport to venturing everywhere in Bangkok by bicycle, might have huge payoffs for people's health, but they might be outweighed by the problems accustomed to urban cycling due to exposure to air pollution (Hartog et al. 2011). However, Thailand has one of the highest traffic accident fatality rates in the world (Ditsuwan et al. 2011).

Cycling is becoming more popular in Bangkok and it is helping the Thai economy both directly and indirectly. Not only do the sales of bicycles and merchandise contribute immensely, but also the improved health of the cyclists and that cycling also enhances productivity, helps to improve the quality of life, and extends one's life expectancy.

However, the benefits of cycling have been well documented, for both the cyclist and society. In a recent study carried out in the United States, it examined physical activity, suggested that those who cycle or walk, are more likely to be fitter and less likely to be overweight or obese than those who prefer to use public or private transport (Gordon-Larsen et al. 2005). Data collected from international surveys of travel behavior and health indicators highlighted those countries with the highest level of cycling and walking have the lowest level of obesity (Bassett et al. 2008).

\section{RESEARCH METHODS}

This article was set up to evaluate the potential of Bangkok becoming a safe-haven for cyclists. This overview considers the potential benefits and risks that cyclist might encounter while cycling on the roads of Bangkok. This research paper was based on some research articles and abstracts that were developed using a combination of the following keywords: active transportation, cycle, cycling, physical activities, and benefits from cycling, safety implications, health, air pollution, and noise exposure. The secondary research was conducted to analyze opinions and aspects in cycling in urban spaces both in Thailand and comparing similar studies carried out in other urban areas.

All identified papers were screened for relevance using the title and/or abstract. An in-depth research study was conducted using qualitative research methodology (i.e., through structured in-depth interviews) and took place from September 20th to October 3rd, 2014. In this survey, respondents were 
cyclists aged 20 to 30 years old and predominantly males.

\section{RESEARCH AND DISCUSSIONS}

There is evidence that children and adolescents in Bangkok began to suffer from the lack of exercise which is adding to the effects of their health. Cardiorespiratory endurance and muscular fitness need urgent attention. In adults, there is a growing risk of premature death notably from heart disease, stroke, type-2 diabetes, high blood pressure, colon, and breast cancer (Oja et al. 2011). These are areas which can easily be addressed by cycling or taking regular exercise (Wee 2017). Cycling 16 miles $(25.5 \mathrm{~km})$, equates to 800 calories, or 4 bags of crisps or 6 cans of Coke. Cycling is a relatively economical and important activity in the promotion of health in most countries (Bassett et al. 2008).

Active transportation is effective because it provides a means for individuals to incorporate moderate intensity activity into their daily routines. This has been shown to be more sustainable over time than structured activity programs like running or going to the gym, yet has similar health benefits, (Dunn et al. 1999). This has been backed up by evidence that people who commute by active transportation get more physical activity on average than people who use motorized transportation (Bueler et al. 2011). Thus, increasing the benefits of cycling would offer a promising way to address the wide- spread level of inactivity and overweight within the Thai Population.

\subsection{Obesity}

In the last twenty years, obesity in Thailand has increased by more than 2.5 times. The prevalence of overweight and obesity among children and adolescents has increased dramatically over the past thirty years. The obesity rate among Thai adults was increasing dramatically, especially among the affluent urban population.

The World Health Organization (WHO) documented in 2004, that over 155 million children around the world were overweight or obese (WHO, 2016). The WHO predicted that by $2015 ; 57 \%$ of women and $35 \%$ of males are overweight (Wee, 2017). At least $45 \%$ of premature deaths in Thailand could be prevented through healthy diet and regular physical activities such as cycling.
Table 1. The most common causes of death that could be prevented by cycling in Thailand.

\begin{tabular}{lc}
\hline Cancer & $19 \%$ \\
Ischemic Heart Disease & $12 \%$ \\
Stroke & $10 \%$ \\
Diabetes & $4 \%$ \\
\hline
\end{tabular}

Source: Wee. 2017.

Cycling in Bangkok is surely becoming more popular. In a survey carried out in Bangkok in 2014, 97\% of our sample participants considered the fact that cycling was becoming more popular. This seems to be replicated around the world especially in $\mathrm{Eu}-$ rope and America.

Many studies have been conducted showing the benefits of cycling (Hartog et al. 2010). In addition, many studies around the world have demonstrated the economic cost due to the lack of physical activity. In Canada for example, the cost incurred due to the lack of physical activity and obesity in 2001 accumulated to $\$ 5.3$ billion and $\$ 4.3$ billion, respectively (Teschke et al. 2012) whereas in Thailand (Pitayatienanan et al. 2014) the cost incurred because of obesity was estimated $\$ 404$ million or 12 billion Baht annually. In contrast from our findings, $70 \%$ of our sample participants considered that the benefits from cycling outweighed the disadvantages and in the same survey $66 \%$ considered that the people in Bangkok were getting healthier compared to $17 \%$ who believed they are not getting healthier and $17 \%$ who believed that there are no changes at all in their health conditions.

Our qualitative research also focused on pollution. Bangkok is well known for its toxic pollution levels (Vichit-Vadakan et al. 2008). Pollution creates a whole new range of problems especially those concerned with non-accidental mortality of which from one research study in Bangkok estimated that there were 95 deaths per day, which were attributed from this proximate cause (Vichit-Vadakan et al. 2008). Our study asked the question: 'Where do you think Bangkok ranks as far as air pollution goes?' $30 \%$ considered it to be very high, $46 \%$ presumed it is just high, $18 \%$ believed it is average, whereas $4 \%$ suggested that it is low and $2 \%$ guessed it is very low. However, interestingly those who travel by motorized transportation are at much higher risk of nonoccupational exposure to air pollutants caused by motorized traffic than what cyclists or pedestrians are (Van Wijnen et al. 1995) and more recently by (Zuurbier et al. 2010). In our survey when the following question was asked: 'How do you evaluate the risk of gaining respiratory damage from air pollution?' $32 \%$ considered it as being a very high possibility, while $38 \%$ suggested that it is a strong likelihood, $20 \%$ considered it as being a medium risk, while $10 \%$ considered it as being a low-risk factor. 


\section{CONCLUSION}

Although cycling in Bangkok is laden with dangers, pollution, and noise to potential accidents, cycling still has offers some advantages. Even in Thailand the odds of being killed are still reasonably low, especially if you consider what the alternatives are. More people die in Thailand from Cancer, Ischemic heart disease, Stroke, and diabetes, all of which could have been prevented by cycling or by participating in other forms of exercise.

Cycling fires up your neurotransmitters, enabling you to improve your ability to concentrate and retain information, thus making you a smarter person. On the environmental side, cycling is environmentally friendly activity and one can reach destinations much faster by cycling than by traveling by car, thus saving you money. For whatever reason, the population in the industrialized countries and part of the developing world seems to be less physically active. The Public Health England has suggested that middle-aged people participate $20 \%$ less in physical activities than they did in the 1960s (Triggle-Heath 2017).

\section{REFERENCES}

Bassett, J.D., Pucher, J., Buehler, R., Thompson, D.L., \& Crouter, S.E. 2008. Walking, cycling, and obesity rates in Europe, North America and Australia. Journal of Physical Activity and Health: 795-814.

Bueler, R., Poucher, J., Meron, D., \& Bauman, A. 2011. Active travel in Germany and the U.S. contributions of daily walking and cycling to physical activity. American Journal of Preventive Madicine 41(3): 241-250.

Ditsuwan, V., Veerman, L.J., Barendregt, J.J., Bertram, M., \& Vos, T. 2011. The national burden of road traffic injuries in Thailand. Population Health Metrics.

Dunn, A., Marcus, B., Kampert, J., Garcia, M., Kohl, H., \& Blair, S. 1999. Comparison on lifestyle and structure intervention to increase physical activity and cardiorespiratory fitness: a randomized Trial. JAMA 281(4): 335-375.

Gordon-Larsen, P., Nelson, M.C., Beam, K. 2005. Associations among active transportation, physical activity, and weight status in young adults. Obesity Research Baton Rouge 13(5): 868-875.

Hartog, J.J., Boogard, H., Niijland, H., \& Hoek, G. 2011. Do the health benefits of cycling outweigh the risks? Environmental Health Perspectives 16(12): 4731-4744.

Oja, P., Titze, S., Bauman, A., de Geus, B., Krenn, P., RegerNash, B., \& Kohlberger, T. 2011. Health benefits of cycling: a systemic review. Scandinavian Journal of Medicine \& Science in Sport.

Pitayatienanan, P., Butchon, R., Yothasamut, J., Aekplakorn, W., Teerawattananon, Y., Suksomboon, N., \& Thavorncharoensap, M. 2014. Economic cost of obesity in
Thailand: a retrospective cost-of-illness study. BMC Health Service Research.

Teschke, K., Harris, A.M., Reynolds, C.C., Winters, M., Babul, S., Chipman, M., \& Cusimano, M.D. 2012. Route infrastructure and risk of injuries to bicyclists: A casecrossover study. American Journal of Public Health 102(12): 2336-2343.

Van Wijnen, J.H., Verhoeff, A.P., Jans, H.W., \& Van Braggen, M. 1995. The exposure of cyclists, car drivers and pedestrians to traffic related air pollution. International Archives Occupational and Environmental Health 67(3): 187-193.

Vichit-Vadakan, N., Vajanapoom, N., \& Ostro, B. 2008. The public health and air pollution in Asia (PAPA) project: Estimating the mortality effects of particulate matter in Bangkok, Thailand. Environmental Health Perspectives 116(9): 1179-1182.

Wee, R.Y. 2017. Leading Causes of Death in Thailand. Society.

WHO. 2016. Global Report on Diabetes. World Health Organisation.

Zuurbier, M., Hoek, G., Oldenwening, M., Lenters, V., Meliefste, K., \& Van Den, H. 2010. Commuters' exposure to particulate matter air pollution is affected by mode of transport, fuel type and route. Environmental Health Perspect 118(6): 783-9. 